\title{
Spontaneous pneumoperitoneum and other nonsurgical causes of intraperitoneal free gas
}

\begin{abstract}
Summary
Intraperitoneal free gas seen radiologically as air under the diaphragm nearly always indicates a perforated abdominal viscus that requires surgical intervention. Rarely, however, the presence of a pneumoperitoneum may not indicate an intra-abdominal perforation and thus may not require laparotomy. Such a situation is termed spontaneous or nonsurgical pneumoperitoneum. In this review, we explore the aetiological mechanisms and the pathophysiology of the appearance of intra-abdominal free gas. An appreciation of the condition and its likely aetiological factors should improve awareness and possibly reduce the imperative to perform an emergency laparotomy on an otherwise well patient with an unexplained pneumoperitoneum.
\end{abstract}

Keywords: pneumoperitoneum, pneumothorax, pneumomediastinum

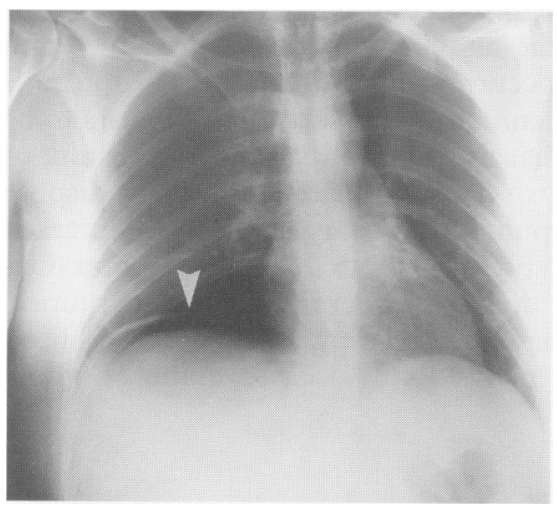

Figure 1 Intraperitoneal free gas is most often seen as air under the diaphragm (arrow)

Department of Surgery, Leicester Royal Infirmary, Leicester LE1 5WW, UK

NMA Williams

DFL Watkin

Correspondence to $\mathrm{Mr} \mathrm{N}$ Williams, Department of General Surgery, The Glenfield Hospital NHS Trust, Groby Road, Leicester LE3 9QP, UK

Accepted 21 August 1996

\section{NMA Williams, DFL Watkin}

The term pneumoperitoneum is used to describe the presence of free gas within the peritoneal cavity but outside the viscera. In the majority of cases $(>90 \%)$ it is the result of perforation of an intra-abdominal viscus. Generally, prompt surgical intervention is required in these patients to reduce the degree and magnitude of enteric contamination within the peritoneal cavity. Consequently, the presence of intraperitoneal free gas usually mandates surgical referral and often results in an emergency laparotomy. There is, however, a subgroup of patients with pneumoperitoneum in whom there are no positive findings. These patients are classified as having 'spontaneous', 1,2 'misleading', 3 or 'nonsurgi$\mathrm{cal}^{4,5}$ pneumoperitoneum. In this review we explore various aetiological mechanisms of the appearance of free intraperitoneal gas which do not usually require laparotomy.

\section{Radiological diagnosis}

The value of a chest X-ray in the visualisation of intraperitoneal free gas was first suggested by Popper in 1915 who detected subphrenic collections of gas in the diagnosis of perforated peptic ulcer (figure 1). ${ }^{6}$ Vaughan and Brams demonstrated the presence of subphrenic free gas in 26 of 29 proven cases of acute perforation of peptic ulcers ${ }^{7}$ and subsequent series confirmed an 87$100 \%$ accuracy for the detection of free gas on an erect chest X-ray. ${ }^{8}$ An alternative radiological sign suggesting intraperitoneal free gas was described by Rigler in 1941, as the ability to visualise the outer as well as the inner wall of the bowel on plain X-ray in the supine position (figure 2). ${ }^{9}$

\section{Intrathoracic causes}

The association of a pneumothorax or pneumomediastinum and the presence of a pneumoperitoneum have been recognised for many years. Eisen described the case of a four-year-old boy with a foreign body in the oesophagus. ${ }^{10}$ Attempts at removal was complicated by a period of increased ventilatory pressure following which the child developed surgical and mediastinal emphysema and a pneumoperitoneum. The child was managed conservatively and recovered without further sequelae. Macklin performed basic scientific studies by the transbronchial placement of a catheter into the lungs of a cat and insufflated with blasts of air at pressures of between 25 and $130 \mathrm{cmH}_{2} \mathrm{O} .{ }^{11}$ If the pressure was high and prolonged, then in addition to subcutaneous emphysema, there was also pneumomediastinum and air around the aorta and in both pleural cavities. Surprisingly, air could also be found in the peritoneal cavity and the retroperitoneum, particularly around the loose perirenal fascia. Post-mortem and microscopic examination suggested that air had entered through tiny openings in the alveoli into the interstitial tissues and thence along the perivascular sheaths of the lung and into the mediastinum. If pressure is continued, air dissects its way downwards along the oesophagus and aorta into the retroperitoneal tissues. Ultimately, rupture of the peritoneum leads to the escape of free gas and the production of a pneumoperitoneum. Subsequent work by the Macklins further consolidated their contention that the passage of air from the chest to the peritoneal cavity was via the perivascular sheaths. ${ }^{12}$ Comparison of clinical observations with Macklin's experimental findings led Eisen to conclude 'the distribution of the gas in the experimental animals, as compared to that in our patient, offers such a striking parallelism as to leave little doubt that the pathways followed must have been the same'. ${ }^{10}$

Spontaneous pneumothorax is a relatively common condition accounting for up to $0.2 \%$ of all hospital admissions although very few of these are ever associated with a pneumoperitoneum. ${ }^{13}$ This is primarily because intra- 


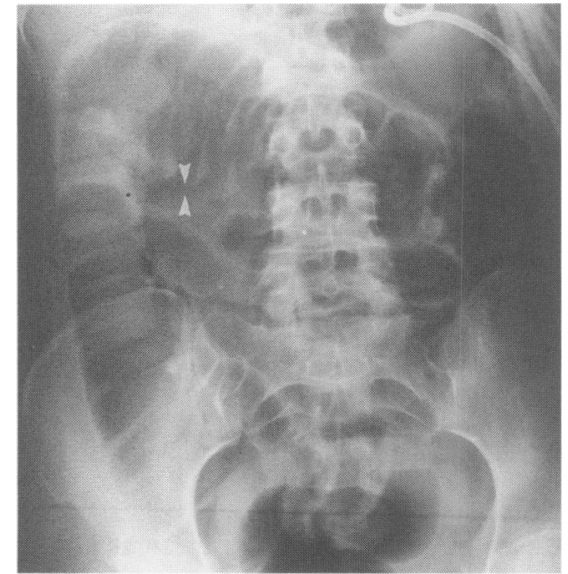

Figure 2 Radiograph demonstrating the presence of Riglers sign (the ability to visualise both the inner and outer wall of the bowel [arrows]), following PEG insertion abdominal pressure usually exceeds intrathoracic pressure by $20-30 \mathrm{cmH}_{2} \mathrm{O}$ during both inspiration and expiration. ${ }^{14}$ However, the association of increased intrathoracic pressure reverses this gradient and at pressures over $40 \mathrm{cmH}_{2} \mathrm{O}$ interstitial emphysema results, over $50 \mathrm{cmH}_{2} \mathrm{O}$ results in pneumoperitoneum and over $60 \mathrm{cmH}_{2} \mathrm{O}$ creates both pneumoperitoneum and surgical emphysema. ${ }^{15}$ The perivascular space is not the sole communication pathway between the chest and abdomen, since both pneumothorax and pneumomediastinum have been described as complications of pneumoperitoneum. Air may traverse the aortic and oesophageal hiatus or enter via congenital defects that may exist between the peritoneal and thoracic cavity ${ }^{16,17}$ or from a pleuroperitoneal fistula. 18

\section{TRAUMA}

Any condition causing a rise in intrathoracic pressure may also result in a pneumoperitoneum. Such cases are clearly very difficult to manage and create a major surgical dilemma. ${ }^{19}$ In these circumstances a high index of suspicion is required and in the absence of clinical signs of intra-abdominal pathology or contrast radiological evidence of enteric perforation then a conservative approach may be adopted. ${ }^{19}$

\section{CARDIOPULMONARY RESUSCITATION}

Pneumoperitoneum may develop following cardiopulmonary resuscitation when the aetiology is most commonly from a ruptured viscus, either the stomach $^{20,21}$ or the oesophagus. ${ }^{22}$ Rarely, however, no cause can be identified. $^{23}$ The therapeutic dilemma is that visceral perforation may not always be detected by contrast examination ${ }^{20,21}$ but the converse is that negative laparotomy may result in mortality. ${ }^{24}$ Some suggest that if pneumoperitoneum is accompanied by radiological evidence of pneumothorax or pneumomediastinum, then a nonoperative strategy may be employed. ${ }^{4,19}$ However, pneumomediastinum was present in at least one reported case accompanied by a gastric perforation and therefore the presence of pneumothorax or pneumomediastinum cannot be taken to exclude visceral perforation. ${ }^{21}$ Conversely, the absence of pneumothorax or pneumomediastinum does not indicate that pneumoperitoneum is the result of visceral perforation and in such cases laparotomy may be negative. ${ }^{23,24}$ Suffice it to stress that nonoperative management should not be contemplated unless visceral perforation can be confidently excluded.

\section{VENTILATED PATIENTS}

Patients receiving positive end-expiratory pressure (PEEP) and continuous positive airway pressure therapy are at risk of spontaneous pneumoperitoneum. The 'air leak' phenomenon is a well recognised consequence of PEEP therapy in which there is rupture of an alveolar air cell into the perivascular and peribronchial interstitial tissues. ${ }^{25}$ The occurrence of such alveolar rupture is not directly related to the magnitude of ventilatory pressure ${ }^{26}$ but appears to be related to the condition of the lung so that unequal ventilation of one lung or segment of lung in the presence of patchy or diffuse disease seems to predispose to the air leak phenomenon. ${ }^{27}$ Loss of pulmonary compliance and decreased elastic recoil of the lung parenchyma also predisposes to this phenomenon. Gas may then dissect into the mediastinum and subsequently into the peritoneal cavity. In a survey of 92 patients receiving PEEP therapy, Altman and Johnson found evidence of pneumoperitoneum in four (4.3\%) cases, none of whom needed operative management. ${ }^{25}$

\section{INTRATHORACIC SEPSIS}

There are several isolated case reports of spontaneous pneumoperitoneum associated with pulmonary sepsis. Britt $e t$ al described the incidental discovery of pneumoperitoneum on pre-operative chest X-ray in a 53-year-old woman with pulmonary tuberculosis who was to undergo elective pulmonary resection. ${ }^{28}$ In the absence of abnormal abdominal signs and normal contrast radiology, she was managed conservatively. Four days after the pneumoperitoneum was noted the patient exhibited symptoms and signs of a respiratory tract infection. Conservative management for the pneumoperitoneum was continued, without subsequent sequelae. Sidel and Wolbarsht report a similar case in which a 62-year-old man was admitted with symptoms and signs suggesting a left-sided pneumonic process and was found to have pneumoperitoneum on chest X-ray as well as signs of a pneumonic process. ${ }^{29}$ Pneumococcal pneumonia was subsequently confirmed. Conservative management of the pneumoperitoneum was successful. A further case is documented by Greenberg and Kahn, in which the aetiological factor was found to be 


\begin{tabular}{|l|}
\hline Intrathoracic and \\
gynaecological causes of \\
pneumoperitoneum \\
\hline Intrathoracic \\
- positive pressure ventilation \\
- pneumothorax/pneumomediastinum \\
- pulmonary sepsis \\
- thoracic trauma \\
- bardiopulmonary resuscitation \\
Gynaecologic \\
- vaginal douching \\
- post-partum exercises \\
- oral-genital insufflation \\
- coitus \\
\hline
\end{tabular}

Klebsiella pneumonia and abscess formation. ${ }^{30}$ The pathophysiology of pulmonary sepsis in the genesis of pneumoperitoneum appears to be two-fold. Small abscess formation adjacent to alveolar or bronchiolar walls may arise as a result of the pneumonic process. Tissue necrosis at such sites results in a pneumothorax and the subsequent formation of interstitial emphysema. ${ }^{30}$ Secondly, the presence of atelectasis in a part of the lung with adjacent hyperinflation may produce a pressure difference between alveoli abutting on pulmonary vessels and the vessels themselves, thus predisposing to the production of a pneumomediastinum. Both these situations may occur with pulmonary sepsis and from the Macklin theory it is possible therefore to explain the association of intrathoracic sepsis and pneumoperitoneum. ${ }^{11,12}$

\section{Gynaecological}

The fact that the genital tract in the female communicates with the peritoneal cavity forms the basis upon which tubal patency is assessed laparoscopically in patients being investigated for infertility. Dye insufflated via the external os can be seen emerging from the fimbrial ends of a patent salpinx. This portal therefore provides a route of access to the peritoneal cavity via which air or fluid may enter under a variety of circumstances. This was recognised many years ago, and in 1875, the French Academy of Medicine took a consideration of communications from its members relating their experience with 'cases of penetration of air into the peritoneal cavity through the uterus and tubes'. ${ }^{2}$ At that meeting deMartiartu presented four cases from his personal experience in which air had entered the peritoneal cavity after being forced through the uterine tube by high pressure vaginal douching. ${ }^{31}$ Other cases of pneumoperitoneum following vaginal douching have been reported, all of which settled with conservative management. ${ }^{32}$ Air may also enter the peritoneal cavity in patients assuming the knee-chest position for post-partum exercises. Dodek states 'the entrance and retention of air in the lower genital tract of the female may occur spontaneously or can be accomplished voluntarily'. 2 Why this phenomena should occur is not quite clear. Lozmann and Newman, however, quote the results from early physiological investigations which demonstrate a positive pressure in the pelvis on assuming upright posture and a negative pressure in the knee-elbow position. ${ }^{33}$ It is suggested that in the latter position, as the abdominal viscera falls towards the head, a negative pressure exists in the pelvis and therefore creates suction. Whether or not the anatomy of the lower genital tract in the postpartum period allows the passage of air more readily remains speculative. In certain instances, air entry by this route may then pass into the blood stream through a break in the continuity of a vein or artery, causing death from air emboli. ${ }^{34}$ The appearance of pneumoperitoneum following pelvic examination in the postpartum period has also been documented. $^{35}$ The risk of pneumoperitoneum is not confined to the postpartum period, however, as Wright reports the case of a 25 -year-old woman who developed pain and a pneumoperitoneum after bending over to tie her laces. The diagnosis of pneumoperitoneum resulting from tubal insufflation was made at laparotomy and subsequently she was managed by wearing a cervical diaphragm. ${ }^{36}$ - Pneumoperitoneum may result from oral-genital insufflation. Freeman reports a 23-year-old woman who presented with abdominal pain and pneumoperitoneum on chest X-ray. There were no signs of peritonitis, she was apyrexial and had a normal white cell count. Laparotomy was therefore deferred. Further questioning revealed that her husband had been blowing air into her vagina at the time the pain began. Following nonoperative management she recovered completely. ${ }^{37}$ Daly reports a similar case in which the patient settled on conservative management. ${ }^{38}$ Unfortunately, in the report by Gantt et al, the history of oral-genital insufflation was only obtained after a negative laparotomy had been performed, ${ }^{4}$ while the patient presented by Varon underwent two negative laparotomies before the history of oral-genital insufflation was elicited. ${ }^{39}$ These cases are indeed fortunate as oral-genital insufflation has more commonly been reported to result in fatal air embolism. ${ }^{34}$ Tabrisky et al report the case of a 40-year-old woman, who had previously had a vaginal hysterectomy, presenting with abdominal pain and a pneumoperitoneum. In the absence of other compelling physical signs she was managed conservatively and without further sequelae. ${ }^{40}$ After her second admission three weeks later, the temporal association of the onset of pain at the time of coitus was recognised. A similar case of pneumoperitoneum occurring after coitus and cunnilingus in a patient who had had a vaginal hysterectomy 13 months previously is presented by Spaulding and Gallup. ${ }^{41}$ In this case a fistulous track from the left fornix to the peritoneal cavity was corrected surgically, following which she remained asymptomatic. This case and that reported by Wright ${ }^{36}$ 
illustrates a successful outcome after surgical and mechanical barriers to the external os are created and adds credence to the belief that in the above cases the portal of entry was indeed the lower genital tract. In all these cases a history of oral-genital insufflation or coitus temporally associated with the onset of pain would allow laparotomy to be deferred and the patient observed further to confirm the aetiology.

\section{Abdominal causes}

\section{PNEUMOTOSIS CYSTOIDES INTESTINALIS}

Pneumotosis cystoides intestinalis probably accounts for a significant proportion of those abdominal causes of pneumoperitoneum not resulting from a ruptured abdominal viscus ( 11 of 29 patients in one large series ${ }^{3}$ ). Pneumotosis cystoides intestinalis is a curious condition in which gases form in the submucosal and subserosal spaces. Although John Hunter first recognised this condition and contributed two specimens from hog intestine to the museum of the Royal College of Surgeons that demonstrated multiple gas-filled cysts beneath the serosal layer, the first pathologic description is attributed to DuVernoi from a cadaver dissection in 1730 . It is generally considered to be a primary idiopathic phenomenon or secondary to another clinical condition such as chronic obstructive airways disease, connective tissue diseases, asthma, peptic ulcer, and intestinal obstruction. ${ }^{38,42}$ Of 213 cases reviewed, Koss found that $85 \%$ were secondary to other underlying causes. ${ }^{43}$ Theories of aetiology include a mechanical theory in which air originates from the chest and reaches the abdomen via a perivascular plane, supporting the association with chronic obstructive airways disease, ${ }^{44}$ a bacterial theory in which gas-producing organisms are thought to penetrate the intestinal mucosa producing cysts, an inflammatory process, and several others. ${ }^{45}$ Recent work suggests the probable source of these gas cysts is the bowel lumen. ${ }^{45}$ Rupture of a cyst appears to be more likely in secondary pneumotosis cystoides intestinalis, although patients with gross radiological evidence of the condition appear to follow a more benign clinical course. Its prompt recognition as an aetiological factor in the genesis of pneumoperitoneum has led to many cases being successfully managed nonoperatively when no other signs of peritonitis have been present. ${ }^{38}$

\section{AFTER GASTROINTESTINAL ENDOSCOPY}

Perforation of the gastrointestinal tract is a well-recognised complication of endoscopic examination. This may become apparent during the examination as the viscus being examined may suddenly become deflated. ${ }^{46}$ Schiff reported the case of a 77-year-old man undergoing gastroscopy. The examination was unremarkable other than for the finding of atrophic gastritis and so the patient commenced fluids and diet two hours after the procedure. ${ }^{47}$ Four days later he attended for a barium meal and was found to have pneumoperitoneum on preliminary radiographic screening. In the absence of any physical signs he was managed conservatively and had a successful outcome. In this case it is not possible to refute that there may in fact have been a genuine gastric perforation with early resealing. However, in the case presented by Schindler, a 40-year-old man developed signs of a pneumoperitoneum very rapidly after gastroscopy and therefore had a laparotomy three hours later. At laparotomy no source of gastrointestinal perforation or rupture was found despite there being air in the peritoneal cavity. ${ }^{46}$ Similar cases in which no perforation was found at laparotomy have also been reported. ${ }^{48}$ Although pneumoperitoneum following gastroscopy is extremely rare, ${ }^{42}$ it may be successfully managed by a conservative approach if there are no signs of peritonitis. ${ }^{48}$ All the reported gastroscopic cases without obvious perforation occurred with the semi-rigid gastroscope. Perforation of the bowel following colonoscopy is a recognised complication, occurring in $0.1-0.8 \%$ of all examinations. ${ }^{50,51}$ It is more common following therapeutic than diagnostic endoscopy. Nearly all cases have positive physical signs as well as radiological pneumoperitoneum. Optimum management is controversial, though a conservative approach has been successful where the complication followed polypectomy, when the defect is often small. ${ }^{52}$

Pneumoperitoneum after percutaneous endoscopic gastrostomy occurs in $30-40 \%$ of patients (figure 2 ). ${ }^{53}$ It usually settles within a week after surgery but may persist for several months. ${ }^{54}$ In such circumstances, pneumoperitoneum is usually benign although negative laparotomy has been reported in this situation when the pneumoperitoneum had persisted for five weeks. ${ }^{55}$ It is therefore important to recognise that the pneumoperitoneum may be present for several weeks and in the absence of other physical signs, a continued conservative approach is warranted. Pneumoperitoneum has also been 
described following endoscopic placement of a biliary stent for a postcholecystectomy bile leak. ${ }^{56}$

\section{IATROGENIC CAUSES}

The commonest iatrogenic cause of pneumoperitoneum is following abdominal surgical procedures. Although it cannot be said to be spontaneous or nonsurgical, it is discussed briefly as its oversight may lead to an unnecessary operation. The duration of the postoperative pneumoperitoneum represents a window of risk during which period the presence or absence of further intraabdominal pathology may be difficult to ascertain. Early reports suggested resolution of free air by seven days postoperatively. ${ }^{57}$ Harrison et al demonstrated that, in the great majority of cases, postoperative pneumoperitoneum is absorbed within two weeks and concluded: 'The possibility of pneumoperitoneum being due to trapped air should not be used as a reasón for delaying exploration when the clinical signs indicate it'. ${ }^{58}$ The case described by Hill et al illustrates the converse situation, in which pathology is thought to exist, resulting in prompt surgical intervention where this may not be necessary. ${ }^{59}$ They report the case of a 54-year-old man who, having undergone elective vagotomy and gastroenterostomy, presented 11 days later (four days after discharge) with abdominal pain and signs of generalised peritonitis. Chest $\mathrm{X}$-ray revealed a marked pneumoperitoneum and although serum amylase was significantly elevated, laparotomy was performed at which the diagnosis of acute pancreatitis was confirmed. In the same paper, Hill et al found that of 70 consecutive patients undergoing laparotomy, $25 \%$ who were clinically well still had radiological signs of pneumoperitoneum after eight days. ${ }^{59}$

Pneumoperitoneum following inguinal herniorrhaphy was documented in one of 32 reported by Harrison et al. ${ }^{58}$ It was probably this observation that prompted conservative management by Halsall and Benson on an 84-year-old man who had had an irreducible inguinal hernia repaired four days previously, when he developed upper abdominal discomfort and was found to have a small pneumoperitoneum on chest X-ray. However, his condition deteriorated and laparotomy confirmed a perforated duodenal ulcer. ${ }^{60}$ O'Brien described the bizarre case of pneumoperitoneum occurring as a result of vesical rupture following urethral catheterisation. ${ }^{61}$

Patients receiving peritoneal dialysis may present a further diagnostic challenge as pneumoperitoneum appears to be relatively common $(20-35 \%$ of patients studied) following dialysis. ${ }^{62}$

\section{Paediatric}

In children and neonates, pneumoperitoneum is nearly always the result of a perforated intra-abdominal viscus. ${ }^{63}$ However, spontaneous pneumoperitoneum is increasingly being recognised in paediatric practice. Porter described spontaneous pneumoperitoneum in a newborn without evidence of gastrointestinal perforation. ${ }^{64}$ Although it was felt that air may have entered from the mediastinum, this was not substantiated. In the case described by Leninger, spontaneous pneumoperitoneum in a newborn was probably the result of a tension pneumothorax as chest drainage resulted in complete resolution of the pneumoperitoneum. ${ }^{65}$ More recently, the association of pneumoperitoneum in the presence of respiratory disease has been highlighted. ${ }^{66}$ Over a two-year period, Leonidas et al identified nine cases of pneumoperitoneum in 222 newborn infants treated with ventilatory assistance. ${ }^{67}$ Four of these were found to be due to perforation of the gastrointestinal tract, but in four cases no gastrointestinal perforation was apparent and in two of these laparotomy was negative. Clinical signs were found to be extremely difficult to evaluate in the neonate, particularly in the presence of respiratory disease. For this reason Leonidas suggests 'a full radiological investigation, including abdominal X-ray films, with the patient upright and opacification of the gastrointestinal tract with water-soluble contrast material, should be carried out in every newborn with pneumoperitoneum and respiratory disease, especially when ventilatory assistance has been applied'. ${ }^{67}$ Using such an approach, Zerella report on five cases of pneumoperitoneum in newborns, all successfully managed by a conservative approach based on the above principles. ${ }^{68}$

\section{Rarities}

Pneumoperitoneum may occur in some very unusual circumstances although in many of these isolated case reports the source of air can be identified. For instance, the case presented by Rose and Jarczyk occurred after scuba diving when an emergency ascent was required and this resulted in decompression 
Indications for surgical intervention in the presence of spontaneous pneumoperitoneum

- onset of abdominal pain

- peritonism/peritonitis

- tachycardia/hypotension

- rising white cell count

- radiology suggests free enteric leak

- failure of conservative management

sickness. ${ }^{69}$ Although chest X-ray revealed no pneumothorax or pneumomediastinum, it is possible that in this case the source of pneumoperitoneum was intrathoracic. Similarly, those cases occurring after adenotonsillectomy ${ }^{70}$ and dental extraction ${ }^{71}$ also had associated respiratory signs and thus the likely source of air was intrathoracic. The case reported by Papp and Sullivan which occurred following aerophagia is quite bizarre and one can only speculate that a spontaneously sealing upper gastrointestinal leak was the aetiology. ${ }^{72}$ Perhaps the most fascinating case is one which occurred following arthroscopy of the knee. ${ }^{73}$

Intra-abdominal sepsis from gas-forming organisms may produce pneumoperitoneum and has been reported following cholecystitis, ${ }^{74}$ salpingitis, ${ }^{75}$ perinephric abscess ${ }^{75}$ and rupture of a pyogenic liver abscess. ${ }^{76}$

\section{Idiopathic}

Finally, there exists a group of patients in whom there are clearly no demonstrable risk factors for the development of pneumoperitoneum and many of these may end up having a negative laparotomy. These are true cases of idiopathic pneumoperitoneum. It was only after a negative laparotomy and no relevant history or radiological findings that the cases described by $\mathrm{Hinkel}^{77}$ and Leys ${ }^{78}$ can be assumed to be idiopathic. In the case described by Gordon and Walkup in which the pneumoperitoneum presented as a scrotal pneumatocele, although laparotomy was completely negative, the patient had had respiratory problems and this may have been the source of the pneumoperitoneum. ${ }^{24}$ In a large single-centre series, four of six patients underwent a negative laparotomy for benign pneumoperitoneum, one of whom died. ${ }^{79} \mathrm{~A}$ cursory survey of our senior colleagues revealed that several had been involved in similar cases of a negative laparotomy for pneumoperitoneum with no other associated risk factors. Perhaps the most unusual and somewhat heartening case is that reported by Hussain and Cox of a 93-year-old woman presenting with a large pneumoperitoneum. ${ }^{80}$ In the absence of any relevant predisposing factors in the history and no significant clinical signs, she was managed conservatively and recovered completely.

\section{Conclusion}

Spontaneous or nonsurgical pneumoperitoneum is uncommon but it is important to identify patients with this condition from among the larger group with intraperitoneal free gas, most of whom have peritonitis and require a laparotomy. As for any rare condition, it is helpful to identify circumstances in which the index of suspicion should be raised; potential iatrogenic cases, eg, recent laparotomy, PEG insertion, and gastrointestinal endoscopy, as well as other predisposing circumstances, such as patients on mechanical ventilation and, in women, gynaecological causes, should be sought. In addition, further radiographic clues may be present, eg, a chest X-ray may demonstrate a pneumothorax and/or pneumomediastinum, or there may be evidence of pneumatosis on the abdominal film. A large amount of intraperitoneal gas is characteristic of idiopathic pneumoperitoneum. In contrast, the presence of intraperitoneal fluid levels on an erect film is usually indicative of pathology.

The fundamental judgement is thus, when there are no abdominal physical signs indicative of peritonitis and the patient is afebrile, with a normal white cell count, then conservative management is indicated. Early involvement of surgical colleagues may aid diagnosis and be helpful in the further management of these patients. Peritoneal aspiration or lavage may provide further reassurance. It is hoped that a greater awareness of the condition and the facilitative diagnostic strategies available may help to reduce the negative laparotomy rate in such patients.

7 Vaughan RT, Brams WA. Roentgen ray in the diagnosis of perforated peptic ulcer. $\mathscr{F} A M A$ 1925; 85: $1876-8$.

1 Madura MJ, Craig RM, Shields TW. Unusual causes of spontaneous pneumoperitone

2 Dodek SM, Friedman JM. Spontaneous pneuDodek SM, Friedman JM. Spontaneous pneumoperitoneum. Obstet Gynecol 1953; 6: 689-98. pneumoperitoneum. Surg Gynecol Obstet 1977; 144: $163-74$.

4 Gantt CB, Daniel WW, Hallenbeck GA. NonGantt CB, Daniel WW, Hallenbeck GA. Non134: $411-4$

5 Hoover EL, Cole GD, Mitchell LS, Adams CZ, Hassett J. Avoiding laparotomy in nonsurgical pneumoperitoneum. Am $\mathcal{F}$ Surg 1992; 164: $99-$ 103.

6 Popper H. Die diagnose der darmperforation mit hilfe der roentgendurchleuchtung. Dtsch Med Wochenschr 1915; 35: 1034-6.
8 Johnson SE. Frequency of air under diaphragm in perforated gastric and duodenal ulcer. Report in perforated gastric and duodenal ulcer. Report
of 42 consecutive cases. $\mathscr{f} A M A 1937 ; 108: 295-$ 6 .

Rigler LG. Spontaneous pneumoperitoneum - a roentgenologic sign found in the supine position. Radiology 1941; 37: 604-7.

10 Eisen D. Surgical emphysema, pneumothorax and pneumoperitoneum. Radiology 1938; 31: $623-5$

11 Macklin CC. Pneumothorax with massive collapse from experimental overinflation of the lung substance. Can Med Assoc ₹ 1937; 36: 189-95.
12 Macklin CC. Transport of air along sheaths of pulmonic blood vessels to mediastinum: clinical implications. Arch Intern Med 1939; 64: 913-6.

13 Glauser FL, Bartlett RH. Pneumoperitoneum in association with pneumothorax. Chest 1974; 66: $536-40$.

14 Rushmer RF. The nature of intraperitoneal and intrarectal pressure. Am $\mathcal{F}$ Physiol 1946; 147: $242-9$

15 Grosfield JL, Boger D, Clatworthy HW. Haemodynamic and manometric observations in experimental air block syndrome. 7 Paediatr Surg 1971; 6: 339-44.

16 Towbin MN. Mediastinal emphysema occurring with therapeutic pneumoperitoneum. Report of 10 cases. Ann Intern Med 1951; 35: 555-7. 
17 Howell G. Spontaneous pneumothorax complicating pneumoperitoneum therapy. $B r \mathcal{F}$ Tuberc 1954; 48: $222-4$.

18 McGlone FB, Vivion CG, Meir L. Spontaneous pneumoperitoneum. Gastroenterology 1966; 51: $393-8$

19 Krausz M, Manny J. Pneumoperitoneum associated with pneumothorax; a surgical dilemma in thepost-traumatic patient. $\mathcal{f}$ Trauma $1977 ; 17$ 238-40.

20 Darke SD, Bloomfield E. Case of complete gastric rupture complicating resuscitation. $B M \mathcal{F}$ 1975; 111: 414-5.

21 Linch D, McDonald A, McNichol L. Tension pneumothorax complicating cardiac resuscitapneumothorax complicating cardiac resur

22 McClure JN, Skardasis GM, Brown JM. Cardiac arrest in the operating area. Am Surg 1972; 38. $240-1$

23 Clinch SL, Thompson JS, Edney JA. Pneumoperitoneum after cardiopulmonary resuscitation a therapeutic dilemma. $\mathcal{f}$ Trauma 1983; 23 428-30.

24 Gordon HL, Walkup JL. Scrotal pneumatocele as an unusual sign of pneumoperitoneum: report of a case and review of the literature. 7 Urol 1970; 104: $441-2$.

25 Altman AR, Johnson TH. Pneumoperitoneum and pneumoretroperitoneum - consequences of and pneumoretroperitoneum - consequences of positive end expiratory pres
Surg 1979; 114: $208-11$.

26 Kumar A, Pontoppichian H, Falke KJ. Pulmonary barotrauma during mechanical ventilation. Crit Care Med 1973; 1: 181-6.

27 Pawner DJ, Snyder JV, Morris CW, et al. Retroperitoneal air dissection associated with mechanical ventilation. Chest 1976; 69: 739-42.

28 Britt CI, Christofordis AJ, Andrews NC. Asymptomatic spontaneous pneumoperitoneum. $A m \mathcal{F}$ Surg 1961; 101: $232-5$.

29 Sidel N, Wolbarsht A. Spontaneous pneumoperitoneum from an unknown cause. $N$ Engl $f$ Med 1944; 231: 450-2.

30 Greenberg LF, Kahn SB. Klebsiella pneumonia with pneumothorax, pneumomediastinum and pneumoperitoneum. Dis Chest 1963; 43: $546-$ 50 .

31 deMartiatu L. Nouveaux documents sur la penetration de l'air dans la cavite du peritoine travers la matrace et les trompes. Gaz Med Paris 1857; 12: 172 .

32 Walker MA. Pneumoperitoneum following a douche. 7 Kansas Med Soc 1942; 43: 55.

33 Lozman H, Newman AJ. Spontaneous pneumoperitoneum occurring during post-partum exercises in the knee-chest position. Am 7 Obstet Gynecol 1956; 72: 903-5.

34 Nelson PK. Pulmonary gas embolism in pregnancy and the peurperium. Obstet Gynecol Survey nancy and the peurpet

35 Cass LJ, Dow E, Brooks KR. Pneumoperitoneum following pelvic examination. $A m \quad \mathcal{F}$ Gastroenterol 1966; 45: 209-11.

36 Wright AR. Spontaneous pneumoperitoneum. Arch Surg 1959; 78: 152-4.

37 Freeman RK. Pneumoperitoneum from oralgenital insufflation. Obstet Gynecol 1970; 36: $162-3$

38 Daly BD, Guthrie JA, Couse NF. Pneumoperitoneum without peritonitis. Postgrad Med $\mathcal{F}$ 1991; 67: $999-1003$.

39 Varon J, Laufer MD, Sternbach GL. Recurrent pneumoperitoneum following vaginal insufflation. Am f Emerg Med 1991; 9: 447-8.
40 Tabrisky J, Mallin LP, Smith JA. Pneumoperitoneum after coitus; a complication due to uterine tube prolapse after vaginal hysterectomy. uterine tube prolapse after vaginal

41 Spaulding LB, Gallup DG. Pneumoperitoneum after hysterectomy. $\mathcal{F} A M A$ 1979; 241: 825.

42 Samach M, Brandt LJ, Bernstein LH. Spontaneous pneumoperitoneum with pneumatosis cystoides intestinalis in a patient with mixed connective tissue disease. Am f Gastroenterol 1978; 69: 494-500.

43 Koss LG. Abdominal gas cysts (pneumatosis cystoides intestinorum hominis). Arch Pathol 1952; 53: 523-49.

44 Keyting WS, McCarver RR, Kovarik JL, et al. Pneumatosis intestinalis: a new concept. Radiology 1961; 76: 733-41.

45 Pierterse AS, Leong ASY, Rowland R. The mucosal changes and pathogenesis of pneumatosis cystoides intestinalis. Hum Pathol 1985; 16: $683-8$.

46 Schindler R. Passage of air through the gastric wall during gastroscopy, with no wound demonstrable three hours later. Gastroenterology 1945 5: $34-6$.

47 Schiff L, Slevens RJ, Goodman S. Pneumoperitoneum following the use of the flexible gastroscope. Ann Intern Med 1941; 14: 1283-7.

48 Ylvisaker RS, Myhre J. Management of pneumoperitoneum after gastroscopy. Gastroenterology 1951; 18: $463-5$.

49 Myhre J, Wilson JA. A study on the occurrence of pneumoperitoneum after gastroscopy and the observance of interstitial emphysema of the stomach. Gastroenterology 1948; 11: 115-9.

50 Smith LE, Nivatvongs S. Complications of colonoscopy. Dis Colon Rectum 1975; 18: 214 20.

51 Hall C, Dorricott NJ, Donovan IA, Neoptolemos JP. Colonic perforation during colonoscopy;
surgical versus conservative management. $B r F$ Surg 1991; 78: 542-4.

52 Christie JP, Marazzo J. 'Mini-perforation' of the colon. Not all post-polypectomy perforations require laparotomy. Dis Colon Rectum 1991; 34: require

53 Gottfried EB, Plumser AB, Clair MR. Pneumoperitoneum following percutaneous endoscopic gastrostomy: a prospective study. Gastrointest Endosc 1986; 32: $397-9$.

54 Thirumahilmaran S, Patel N, Thomas E. Prolonged benign pneumoperitoneum after percutaneous endoscopic gastrostomy. Am $\mathcal{f}$ Gastroenterol 1995; 90: 147-8.

55 Schnall HA, Falkenstein DB, Raicht RF. Persistent pneumoperitoneum after percutaneous endoscopic gastrostomy. Gastrointest Endosc 1987; 33: $248-50$.

56 Bar-Meir S, Lang A, Shemesh E, Nass S, Dreznick Z. Pneumoperitoneum after insertion of endoscopic biliary stent for post-cholecystectomy biliary leak. Gastrointest Endosc 1993; 39, $818-20$

57 Bannen JE. Postoperative pneumoperitoneum Br F Radiol 1944; 17: 119-21.

58 Harrison I, Litwer H, Gerwig WH. Studies on the incidence and duration of postoperative pneumoperitoneum. Ann Surg 1957; 145: $591-4$

59 Hill HF, Bunting J, Wood RD, Temple JG. The significance of radiological pneumoperitoneum in the diagnosis of postoperative peritonitis. $f R$ in the diagnosis of postoperative
60 Halsall AK, Benson EA. Pneumoperitoneum following hernia repair. Br f Surg 1978; 65: 416

61 O'Brien WJ, Ryckman FC. Catheter-induced urinary bladder rupture presenting with pneumoperitoneum. F Paediatr Surg 1994; 29: 1397 8.

62 Svetvilas C, Tannenberg AM. Pneumoperitoneum with peritoneal dialysis. Lancet 1971; i 910-1.

63 Freeark RJ, Raffensperger JG, Gordon JB Pneumoperitoneum in infancy. Surg Gynecol Obstet 1961; 113: 623-6.

64 Porter A. Spontaneous pneumoperitoneum in the newborn. N Engl F Med 1956; 254: 694-6.

65 Leninger BJ, Barker WL, Langston HT. Tension pneumoperitoneum and pneumothorax in the newborn. Ann Thorac Surg 1970; 9: 359-63.

66 Aranda JV, Stern L, Dunbar JS. Pneumothorax with pneumoperitoneum in a newborn infant. Am 7 Dis Child 1972; 123: $163-6$

67 Leonidas JC, Hall RT, Rhodes RG, Armoury RA. Pneumoperitoneum in ventilated newborns a medical or surgical problem. Am f Dis Child 1974; 128: $677-81$.

68 Zerella JT, McCullough JY. Pneumoperitoneum in infants without gastrointestinal perforation. Surgery 1981; 89: 163-7.

69 Rose DM, Jarczyk PA. Spontaneous pneumoperitoneum after scuba diving. $7 A M A$ 1978; 239: 223.

70 Jash DK. An unusual complication during adenotonsillectomy. ₹ Laryngol Otolarygol 1973; 87: $191-4$.

71 Sandler CM, Libshitz HI, Marks G. Pneumoperitoneum, pneumomediastinum and pneumopericardium following dental extraction Radiology 1975; 115: 539 - 40 .

72 Papp JP, Sullivan BH. Spontaneous pneumoperitoneum without peritonitis: report of a case. Cleve Clin Q 1965; 32: 149.

73 Bourne MH, Watson RC, Carmichael SW. Pneumoperitoneum as a complication of carbon dioxide knee arthroscopy. Am $\mathcal{f}$ Sports $\mathrm{Med}$ 1993; 21: $623-5$.

74 Watson DI, Issacs J, Williams RS. Emphysematous cholecystitis can cause pneumoperitoneum. Aust N Z F Surg 1994; 64: 130-1.

75 Poilly JN. Pneumoperitoneum associated with Escherichia coli peritonitis: a report of two cases. Postgrad Med F 1970; 46: 114

76 Matsuyama S, Satoh H, Yunotani S, et al. An unusual presentation of spontaneous pneumoperitoneum secondary to the rupture of a gascontaining pyogenic liver abscess: report of case. Surg Today 1994; 24: 63-6.

77 Hinckel CL. Spontaneous pneumoperitoneum without demonstrable visceral perforation. $A Y R$ 1940; 43: $377-82$.

78 Leys D. Pneumoperitoneum. BMF 1944; ii: 562.

79 Mezghebe HM, Lefall LD, Siram SM, Syphax B. Asymptomatic pneumoperitoneum, diagnostic and therapeutic dilemma. Am Surg 1994; 60 $691-4$.

80 Hussain A, Cox JGC. Benign spontaneous pneumoperitoneum in an elderly patient treated medically with recovery. Postgrad Med f 1995; 71: 252 . 